\title{
A cross-cultural comparison of factors associated with marijuana use among college students in the United States and Sweden
}

\author{
Dana M. Litt ${ }^{1}$, Henriettae Stahlbrandt ${ }^{2}$, Claes Andersson ${ }^{3}$, Mats Berglund ${ }^{4}$, Cassidy R. LoParco ${ }^{1}$, Tracey A. \\ Garcia $^{5}$, Melissa A. Lewis ${ }^{1}$, and Mary E. Larimer \\ ${ }^{1}$ Department of Health Behavior and Health Systems, School of Public Health, University of North Texas Health Science Center, Fort Worth, TX, \\ U.S. \\ ${ }^{2}$ Department of Radiology, Region Jönköping County, Sweden \\ ${ }^{3}$ Department of Health and Society, Malmö University, Sweden \\ ${ }^{4}$ Division of Psychiatry, Department of Clinical Science, Faculty of Medicine, Lund University, Sweden \\ ${ }^{5}$ Department of Psychology, Murray State University, Murray, KY, U.S. \\ ${ }^{6}$ Center for the Study of Health \& Risk Behaviors, University of Washington, Seattle, WA, U.S.
}

\begin{abstract}
Aims: Marijuana is a popular drug among U.S. college students. In Sweden, the prevalence of marijuana use has been relatively low but is increasing. Brief, personalized interventions have been efficacious in reducing substance use, including marijuana, among college students in the U.S. However, prior to implementation of U.S. interventions in Sweden, it is important to compare factors associated with marijuana use among college students in the two countries.

Design, Setting, and Participants: Data are from baseline assessments of two large college student intervention studies in the U.S. $(N=3,753,39 \%$ male $)$ and Sweden $(N=2,280,35 \%$ male $)$.

Measures: Past 30-day prevalence and frequency of marijuana use was analyzed in regard to relevant demographic factors. The moderating role of nationality was also examined.

Findings: Results support previous findings indicating marijuana use is more common in the U.S. than in Sweden. Most demographic factors were similar across the countries, except for relationship status and work status, in which associations with number of marijuana use days (but not odds of any marijuana use) were stronger for Swedish college students compared to U.S. college students.
\end{abstract}

Conclusions: Based on overall similarities between the U.S. and Sweden, comparable interventions might be recommended in both countries.

\section{Introduction}

Marijuana use is associated with several psychosocial and academic problems during college. Specifically, college student marijuana users report more emotional problems including anxiety and depression, greater health service utilization for physical and mental health problems, and lower subjective well-being than non-users (Arria et al., 2016; Keith et al., 2015).

Frequent and long-term marijuana use is associated with both short-term consequences, including decreased cognitive functioning (Karila et al., 2014), as well as longerterm consequences, including addiction, poor educational outcomes, cognitive impairment, lower IQ, diminished life satisfaction, and lower achievement (Arria et al., 2013; Maggs et al., 2015; Volkow et al., 2014).

\section{Need for Cross-Cultural Comparisons}

Given that most marijuana interventions for college students have been developed and tested in the United States (U.S.; Elliott et al., 2014; Lee et al., 2010, 2013; Palfai et al, 2014; Riggs et al., 2018), comparing marijuana use and its correlates across countries is important to determine the generalizability of the large body of research on U.S. college marijuana use to other countries. Recent research examining cross-cultural comparisons involving the U.S. has primarily focused on measure validation. Measures of marijuana

Correspondence: Dana M. Litt, Department of Health Behavior and Health Systems, School of Public Health, University of North Texas Health Science Center, Fort Worth, TX, U.S.

Email: dana.litt@unthsc.edu

Financial support: This research was supported by grant A2010-03 from the Swedish National Institute of Public Health awarded to Dr. Claes Andersson, and grant R01AA012547 from the National Institute on Alcohol Abuse and Alcoholism awarded to Dr. Mary Larimer Declaration of interest: None

Keywords: college students, international, United States, Sweden, drug use, marijuana 
consequences and the perceived importance of marijuana to the college student experience in countries such as the U.S., Argentina, Spain, and Uruguay have been shown to capture these key constructs in the same way, regardless of sex, country or language (Bravo et al., 2019; Pearson et al., 2019. This work highlights the need to continue to study college marijuana use cross-culturally as there may be important similarities, regardless of culture. However, to our knowledge, no work to date has examined U.S. college students' marijuana use in comparison to Nordic countries, such as Sweden. Given that marijuana laws in Sweden are some of the harshest in Europe and the country outright bans any and all possession, sale, transport, and cultivation of cannabis, including medical marijuana (Polisen, 2017), it provides an ideal contrast to the U.S., where legalization of marijuana is becoming increasingly common (Han et al., 2018; Hasin et al., 2017). In addition, this different legalization status across countries is likely to affect the way in which the countries approach harm reduction and treatment, thus providing an even greater need for crosscultural comparisons. Before researchers and clinicians in Sweden and other countries create culturally adapted prevention and intervention strategies developed originally for college students in the U.S., more information is needed to determine demographic factors that may overlap or differ between these countries.

\section{Prevalence and Correlates of College Marijuana Use}

\section{United States}

Among college students in the U.S., lifetime rates of marijuana use range from $42.5 \%$ to $63.6 \%$ with rates of past year use averaging around $38 \%$, past month use at $26.2 \%$, and daily use ranging between $4.4 \%$ and $5.8 \%$ (Pearson et al., 2017; Schulenberg et al., 2018). In addition, an estimated $2.5 \%$ of adults meet criteria for past year cannabis use disorder and of those only $7.2 \%$ report receiving treatment (Hasin et al. 2017). Of additional concern, national data indicate that college students' use of marijuana in 2018 was at the highest level seen in 35 years (Schulenberg et al., 2018). Prior research has found that U.S. college student marijuana users are more likely to be white, male, single, members of fraternities, not engaged in extra-curricular activities, and non-athletes (Buckman et al., 2011; McCabe et al., 2005; Wright \& Palfai, 2012). Research also indicates that living on campus during freshman year is associated with initiation of marijuana use among U.S. college students (Suerken et al., 2014). Thus, college student marijuana use in the U.S. represents a challenge to stakeholders from public health, mental health, and higher education sectors.

\section{Sweden}

In contrast to the U.S, marijuana use is relatively low in Sweden. For example, the rate of lifetime marijuana use among 16-year-olds in Sweden is typically between 4-7\% (ESPAD Group, 2016). Results from the National Swedish Health survey 2018 shows that $17.8 \%$ of students over the age of 16 have a lifetime prevalence of marijuana use, of which $7.8 \%$ have past year usage and $1.9 \%$ past month usage (Folkhälsomyndigheten, 2018). Of individuals entering substance use treatment, approximately $10 \%$ seek treatment specifically for marijuana use (European Monitoring Centre for Drugs and Drug Addiction [EMCDDA], 2019). There are few studies focused on Swedish college students and marijuana use, despite Sweden's views on the susceptibility of young adults to the deleterious effects of marijuana use (Månsson \& Ekendahl, 2015). Swedish university-specific studies have shown higher prevalence, ranging from 18$37 \%$ and $12-41 \%$ for lifetime and past year use respectively (Bloom \& Iordanidis, 2014; Jansson, 2014; Källoff et al, 2015; Lundgren \& Uhlin, 2014). It is important to note that although there is a trend of increased past 12 month marijuana use from $7.3 \%$ in 2015 to $9.6 \%$ in 2017 among persons aged 15-34 years in Sweden (EMCDDA, 2017, 2019), the use of illicit drugs is still uncommon compared to other European countries as well as the U.S. (ESPAD Group, 2016). Given that marijuana use is a relatively less prevalent phenomenon among Swedish young adults as compared to other countries, including the U.S., its correlates may not be the same as those observed in countries with higher prevalence rates (Sznitman et al., 2015). In Sweden, it has been shown that amongst university students, males were more likely to report using all drugs including marijuana (Bloom \& Iordanidis, 2014; Bullock, 2004; Folkhälsomyndigheten 2018; Källof et al, 2015; Lundgren \& Uhlin, 2014). Furthermore, students living with roommates or in dormitories have higher rates of marijuana use than those with other living arrangements (Bullock, 2004). Lundgren and Uhlin (2014) showed that university students who had used marijuana showed a higher involvement in extracurricular activities, compared to those who had not used marijuana. Together, the limited research on Swedish college student marijuana use indicates that there are some similarities between Swedish and U.S. correlates of use, but there are still many factors that are not well understood.

Therefore, before researchers and clinicians in Sweden consider adapting and implementing prevention and intervention strategies developed for college students in the U.S., more information is needed to determine correlates and potential demographic factors that may overlap or differ between these countries. Having a thorough understanding of where commonalities exist has the potential to aid researchers and clinicians in Sweden in their efforts to develop and adapt efficacious U.S. based intervention strategies based on scientific evidence and culturally appropriate indicators of vulnerabilities and patterns of use.

Based on previous studies as described above, we had the following research aims:

Aim 1: to compare rates of marijuana use among U.S. and Swedish college students.

Aim 2: to examine whether specific demographic indicators of marijuana use (sex, age, years in school, full or part-time college enrollment, living situation, relationship status, work status, and involvement in extra-curricular activities) are associated with marijuana use among college students in both countries and whether nationality (U.S. versus Sweden) moderates any of the above associations. 


\section{Method}

\section{Participants and Procedure}

The current study involved a comparison of data collected from two prospective studies of college student marijuana use, one conducted in the U.S. and the second conducted in Sweden.

\section{U.S. Study}

Participants were undergraduate students from two U.S. West Coast universities. Campus $1(n=1,607)$ is a large public research university with an undergraduate enrollment of more than 27,000 students. Campus $2(n=1,091)$ is a private mid-size university with approximately 6,000 undergraduate students. A sample of 7,000 undergraduate students (3,500 from each campus) was selected at random from names and e-mail addresses obtained from the Registrar's office. Students were sent letters and e-mails describing the study and containing a survey link to participate, along with a unique participant identification number. After providing consent, participants were routed to a 25-minute survey, for which they received \$20. All measures and procedures were reviewed and approved by the local institutional review board on both campuses.
Approximately half (54\%) of the students who were invited completed the screening survey $(n=3,753 ; 1,936$ from campus $1 ; 1,817$ from campus 2 ).

The American sample had a mean age of 19.88 years $(\mathrm{SD}=$ $1.36)$ and reported $1.77(\mathrm{SD}=1.46)$ total years in college. Sixty-one percent of the sample were female, and race/ethnicity varied: $57 \%$ White/Caucasian, 20\% AsianAmerican/Pacific Islander/Hawaiian, 3\% Black/African American, 11\% "multiple ethnicities," and 9\% "other ethnicities." See Table 1 for baseline demographics.

\section{Swedish Study}

Data for the Swedish sample were collected as part of a baseline assessment of a longitudinal evaluation of the Swedish National Institute of Public Health campaign on developing methods to reduce harmful drinking at universities. The Swedish research group was responsible for this data collection. The Swedish Agency for Higher Education Services provided 5,648 e-mail addresses for all freshmen entering eight universities. In total 2,280 (40.4\%) of these responded to a web-based survey. The mean age was $22.9(S D=5.64)$, and the mean years at university reported was $0.2(S D=0.64)$. See Table 1 for baseline demographics. The regional Ethics committee approved the procedures for the study.

\section{Table 1.}

\begin{tabular}{|c|c|c|c|c|c|c|c|c|c|c|}
\hline Sample & $\mathrm{N}$ & $\begin{array}{c}\text { Age } \\
(\text { Years } \pm \\
S D)\end{array}$ & $\begin{array}{c}\text { Sex } \\
(\% \text { Male })\end{array}$ & $\begin{array}{l}\text { Years in } \\
\text { School } \\
( \pm \text { SD })\end{array}$ & $\begin{array}{c}\text { Student } \\
\text { Status } \\
\text { (\% Full } \\
\text { Time) }\end{array}$ & $\begin{array}{c}\text { Work } \\
\text { Status } \\
(\% \\
\text { Working) }\end{array}$ & $\begin{array}{l}\text { Relationship } \\
\text { Status (\% in } \\
\text { relationship) }\end{array}$ & $\begin{array}{l}\text { Living } \\
\text { Situation } \\
\text { (\% with } \\
\text { parents) }\end{array}$ & $\begin{array}{c}\text { Extra- } \\
\text { curricular } \\
\text { Sports } \\
\text { Activities (\% } \\
\text { involved) } \\
\end{array}$ & $\begin{array}{c}\text { Extra- } \\
\text { curricular } \\
\text { Non-Sport } \\
\text { Activities (\% } \\
\text { involved) } \\
\end{array}$ \\
\hline$\overline{\text { U.S. }}$ & 3,753 & $19.9 \pm 1.4$ & $38.6 \%$ & $1.77 \pm 1.5$ & $98.0 \%$ & $63 \%$ & $33.7 \%$ & $11.1 \%$ & $23.8 \%$ & $19.5 \%$ \\
\hline Swedish & 2,280 & $22.9 \pm 5.6$ & $34.5 \%$ & $0.2 \pm 0.6$ & $97.6 \%$ & $34 \%$ & $52.7 \%$ & $22.3 \%$ & $78 \%$ & $25.7 \%$ \\
\hline Total & 6,033 & $21.0 \pm 3.9$ & $37.0 \%$ & $1.17 \pm 1.4$ & $97.7 \%$ & $52 \%$ & $40.9 \%$ & $15.3 \%$ & $39.8 \%$ & $21.3 \%$ \\
\hline
\end{tabular}

\section{Measures}

Both studies included comparable measures of the constructs of interest for the current secondary analyses. Measures utilized in the Swedish data collection were translated and back- translated to ensure appropriate content and construct equivalence between the two languages.

\section{Marijuana Frequency}

Marijuana frequency was assessed using a single item: "In the past 30 days, how many days did you use marijuana?" which was answered on a scale ranging from 0 (0 days) to 30 (30 days).

\section{Demographics}

Participants were asked a series of demographic questions, including relationship status (single and single not dating = 0 , stable relationship/married/cohabiting $=1$ ), living situation (alone, fraternity/sorority house/residence hall/dorm rooms, apartment with friends, off-campus housing/apartment/house/with spouse/with children, or other $=0$, living with parents $=1)$. Participants were also asked their student status $(0=$ part-time, $1=$ full-time $)$, work status ( 0 = not working, 1 = working), how many years of college they had attended, and whether they were participating in any extra-curricular activities involving sports $(0=$ no, $1=$ yes $)$ or non-sport extracurricular activities (not involved $=0$, involved $=1$ ). Finally, all participants reported their age, biological sex (male $=0$, female $=1$ ), and race/ethnicity (U.S. sample) or ethnic region of origin (Swedish sample). Because ethnic background was assessed using different measures, this latter information was included to describe the samples but was not used as an independent variable in analyses.

\section{Analysis}

To assess the first aim, we used independent samples $t$-tests to determine whether there were significant differences in prevalence of any marijuana use between countries. Related to the second aim, two regression models were estimated to examine the main effects of nationality, gender, age, living situation, years of college, part- or full-time student status, work status, relationship status, intercollegiate or intramural sports participation, and participation in other non-sport extracurricular activities in the prediction of any marijuana use and the number of days of marijuana use in the past 30 
days. Each model also included interaction terms between each main effect predictor above, and nationality, to determine if nationality moderated any of the above effects (i.e., there were differences between countries). The model testing associations between the predictors and any marijuana use as the outcome was examined using logistic regression. For the model with number of days of marijuana use as the outcome, because of the violation of normality assumption and the positive skew of the data, negative binomial regression was selected as the primary analysis strategy (Atkins et al., 2013; Hilbe, 2011). The two dependent variables, any marijuana use and the number of marijuana use days over the past 30 days, could also be modelled simultaneously using a zero-inflated negative binomial regression model (ZINB; Long, 1997), however the discrepancies between rates of use and days of use across nations led to suppression effects in the ZINB models and the coefficients were not interpretable.

\section{Results}

A total of 6,033 students were included in the analysis, of which $3,753(62.2 \%)$ were from the U.S. and 2,280 were Swedish. For a comparison of baseline demographic data, see Table 1.

\section{Comparison of Marijuana Use}

Related to Aim 1, the use of any marijuana was significantly higher among U.S. college students as compared to Swedish college students. Specifically, $25.1 \%$ of U.S. $(n=942)$ and $6.1 \%$ of Swedish students $(n=140)$ reported any marijuana use in the past 30 days $(t=19.67$ (6031), $p<0.001)$. Results also indicated significant differences between countries on the mean number of marijuana use days in the past 30 days such that U.S. college students used marijuana on more days on average

\section{Table 2.}

Logistic regression predicting any marijuana use in the past 30 days

\begin{tabular}{|c|c|c|c|c|}
\hline Predictors & $\mathrm{B}(S E)$ & OR & OR LCL & OR UCL \\
\hline \multicolumn{5}{|l|}{ Intercept } \\
\hline Nationality & $-1.16(0.90)$ & 0.31 & 0.05 & 1.83 \\
\hline Biological sex & $-0.38(0.08)^{* * *}$ & 0.68 & 0.58 & 0.80 \\
\hline Age & $0.02(0.04)$ & 1.02 & 0.94 & 1.07 \\
\hline Relationship status & $-0.27(0.09)^{* *}$ & 0.76 & 0.65 & 0.90 \\
\hline Years in school & $0.01(0.03)$ & 1.00 & 0.94 & 1.07 \\
\hline Student status & $-0.01(0.26)$ & 0.99 & 0.60 & 1.65 \\
\hline Work status & $0.29(0.08)^{* * *}$ & 1.34 & 1.14 & 1.58 \\
\hline Living situation & $-0.89(0.15)^{* * *}$ & 0.41 & 0.30 & 0.55 \\
\hline Extracurricular sport activities & $0.04(0.09)$ & 1.04 & 0.88 & 1.23 \\
\hline Non-sport extracurricular activities & $0.17(0.10)$ & 1.19 & 0.98 & 1.44 \\
\hline Nationality $\mathrm{x}$ biological sex & $0.36(0.23)$ & 0.70 & 0.44 & 1.10 \\
\hline Nationality $\mathrm{x}$ age & $-0.02(0.04)$ & 0.98 & 0.90 & 1.06 \\
\hline Nationality $\mathrm{x}$ relationship status & $-0.46(0.24)$ & 0.63 & 0.39 & 1.02 \\
\hline Nationality $\mathrm{x}$ years in school & $0.14(0.14)$ & 1.15 & 0.88 & 1.50 \\
\hline Nationality $\mathrm{x}$ student status & $0.47(0.71)$ & 1.61 & 0.40 & 6.41 \\
\hline Nationality $\mathrm{x}$ work status & $0.06(0.24)$ & 1.06 & 0.66 & 1.69 \\
\hline Nationality $\mathrm{x}$ living situation & $-0.14(0.39)$ & 0.87 & 0.41 & 1.85 \\
\hline Nationality x extracurricular sports & $0.06(0.29)$ & 1.06 & 0.60 & 1.87 \\
\hline Nationality x non-sport extracurricular & $0.64(0.35)$ & 1.90 & 0.96 & 3.78 \\
\hline
\end{tabular}

$* p<0.05, * * p<0.01, * * * p<0.001$. OR $=$ odds ratio; $L C L=95 \%$ lower confidence limit $;$ UCL $=95 \%$ upper confidence limit. Note. Nationality $(0=$ American, $1=$ Swedish); Biological sex $($ male $=0$, female $=1)$; Relationship status $($ single $=0$, stable relationship/married/cohabiting $=1)$; Student status $(0=$ part-time, 1 = full-time); Work status (not working=0, working = 1$)$; Living situation (not living with parents $=0$, living with parents $=1$ ); Extracurricular sport activities $($ not involved $=0$, involved $=$ 1); Non-sport extracurricular activities (not involved $=0$, involved $=1$ ).

$(M=1.44, S D=4.74)$ in comparison to Swedish college students $(M=0.93, S D=3.78 ; t=13.33(5,838), p<.001)$. The maximum number of days of use in the past 30 days among Swedish students was eight days $(n=4)$, while the maximum days of use among U.S. students was 30 days ( $n$ $=30)$.

\section{Predictors of Any Marijuana Use}

With regard to Aim 2, results from the logistic regression analyses indicated that biological sex, living situation, work status, and relationship status were all significant predictors of any marijuana use in the past 30 days. In particular, being male, not living with parents, working, and not being in a relationship were all associated with increased odds of using marijuana in the past 30 days. On the contrary, the odds of 
any marijuana use was not significantly associated with nationality, age, number of years in school, part- or full-time student status, participation in sports, or participation in nonsport extracurricular activities. In terms of possible moderation effects, results did not indicate that nationality moderated any of the associations between biological sex, age, relationship status, years in school, part- or full-time student status, work status, living situation, or participation in sport or non-sport extracurricular activities. Refer to Table 2 for full results.

\section{Predictors of Number of Marijuana Use Days}

To further examine Aim 2, we examined all model variables as predictors of the number of marijuana use days (both main effects and interactions) in the past month using a negative binomial regression model. As seen in Table 3, when all predictors were entered simultaneously, nationality, biological sex, years in school, student status, work, living situation, and participation in both sport-related extracurricular and non-sport extra-curricular activities were significantly associated with the number of marijuana use days. Specifically, being a college student in the U.S., male, being in college for longer, being a part-time student, working, not living with parents, and being involved in both sport and non-sport extracurricular activities were associated with using marijuana on more days in the past 30 days. Neither age nor relationship status were significantly associated with number of days of marijuana use. Studying the potential moderating role of nationality, only the interactions between nationality and relationship status and nationality and work status were significant. Specifically, results indicated that the associations between work and relationship status and number of days of marijuana use were stronger for Swedish college students as compared to U.S. college students.

\section{Table 3.}

Negative binomial regression predicting number of marijuana use days in the past 30 days

\begin{tabular}{|c|c|c|c|c|}
\hline Predictors & $\mathrm{B}(\mathrm{SE})$ & IRR & IRR LCL & IRR UCL \\
\hline \multicolumn{5}{|l|}{ Intercept } \\
\hline Nationality & $-2.37(0.55)^{* * *}$ & 0.09 & 0.03 & 0.27 \\
\hline Biological sex & $-0.86(0.05)^{* * *}$ & 0.42 & 0.39 & 0.47 \\
\hline Age & $0.04(0.02)$ & 1.04 & 0.99 & 1.08 \\
\hline Relationship status & $-0.28(0.05)$ & 0.97 & 0.88 & 1.07 \\
\hline Years in school & $0.07(0.02)^{* * *}$ & 1.07 & 1.03 & 1.10 \\
\hline Student status & $-0.93(0.19)^{* * *}$ & 0.39 & 0.27 & 0.57 \\
\hline Work status & $0.09(0.08)^{*}$ & 1.09 & 1.00 & 1.21 \\
\hline Living situation & $-1.08(0.09)^{* * *}$ & 0.34 & .029 & 0.41 \\
\hline Extracurricular sport activities & $0.10(0.05)^{*}$ & 1.11 & 1.00 & 1.23 \\
\hline Non-sport extracurricular activities & $0.31(0.06)^{* * *}$ & 1.36 & 1.22 & 1.52 \\
\hline Nationality $\mathrm{x}$ biological sex & $-0.14(0.18)$ & 0.87 & 0.61 & 1.26 \\
\hline Nationality $\mathrm{x}$ age & $0.01(0.02)$ & 1.01 & 0.95 & 1.06 \\
\hline Nationality $\mathrm{x}$ relationship status & $-0.95(0.19)^{* * *}$ & 0.39 & 0.26 & 0.57 \\
\hline Nationality $\mathrm{x}$ years in school & $0.07(0.09)$ & 1.08 & 0.90 & 1.29 \\
\hline Nationality $\mathrm{x}$ student status & $0.51(0.67)$ & 1.68 & 0.44 & 6.30 \\
\hline Nationality $\mathrm{x}$ work status & $0.60(0.18)^{* * *}$ & 1.82 & 1.27 & 2.62 \\
\hline Nationality $\mathrm{x}$ living situation & $0.14(0.33)$ & 0.87 & 0.45 & 1.67 \\
\hline Nationality $\mathrm{x}$ extracurricular sports & $-0.25(0.20)$ & 0.78 & 0.52 & 1.16 \\
\hline Nationality x non-sport extracurricular & $-0.63(0.45)$ & 0.53 & 0.22 & 1.28 \\
\hline
\end{tabular}

$* p<0.05, * * p<0.01, * * * p<0.001$. IRR $=$ incident rate ratio; $L C L=95 \%$ lower confidence limit $;$ UCL $=95 \%$ upper confidence limit. Note. Nationality $(0=$ American, $1=$ Swedish); Biological sex $($ male $=0$, female $=1) ;$ Relationship status $($ single $=0$, stable relationship $/ \mathrm{married} / \mathrm{cohabiting}=1) ;$ Student status $(0=$ part-time, $1=$ full-time); Work status $($ not working $=0$, working $=1)$; Living situation (not living with parents $=0$, living with parents $=1$ ); Extracurricular sport activities $($ not involved $=0$, involved $=$ 1); Non-sport extracurricular activities (not involved $=0$, involved $=1$ ).

\section{Discussion}

Results indicate that there is more marijuana use, both in terms of any use and the number of days used in the past 30 days, within the U.S. sample than in the Swedish sample, consistent with previous studies. Given that there is a strong anti-drug attitude in Sweden (Tham, 2009) as well as a focus on a zero tolerance policy on marijuana use (Månsson \&
Ekendahl, 2015) and a relatively negative public view about marijuana use (Blomqvist, 2009) which stands in contrast to decreasing perceptions of risk related to marijuana use among young adults in the U.S. (Substance Abuse and Mental Health Services Administration, 2019), the increased odds of any marijuana use and more marijuana use days in the U.S. was not surprising. 
Despite these differences in marijuana use, interesting patterns of potential country-related differences emerged when examining the odds of any marijuana use and the number of days of marijuana use in the past 30 days. Notably, there was no evidence of nationality either serving as a main effect or as a moderator of any of the associations between all factors tested in the current study (nationality, biological sex, age, relationship status, years in school, student status, work status, living situation, and both sport and non-sport extracurricular activities) and the odds of engaging in any marijuana use. However, when examining the number of marijuana use days, results indicated a main effect of nationality such that being a U.S. college student was associated with greater number of marijuana use days. Further, nationality moderated the effects between relationship status and work status on the number of marijuana use days. First, it is clear that while the odds of marijuana use may not differ by country when considered simultaneously with a host of other potential factors, there is a significant effect of nationality on how frequently college students are using marijuana. In terms of specific differences between countries, results only indicated nationality-level differences for relationship status and work status. It is interesting that the association between relationship status and work and frequency of marijuana use were stronger among Swedish students compared to U.S. students. Although our study cannot determine why these differences exist, it is possible that in Sweden, where participants used marijuana less frequently, being in a relationship (which was more likely among Swedish students compared to U.S. students) increased their chances of being exposed to peer norms for marijuana use, which is an important factor related to substance use among college students (Shrier et al., 2012). In terms of the association between work status and number of days of marijuana use being stronger among Swedish students, it is possible that in Sweden (where significantly fewer students work outside of college than in the U.S.), there is something unique about students who seek outside employment that puts them at higher risk for marijuana use. However, the reasons behind these country-level differences are mostly speculative as there is an overall lack of Swedish studies on college students and marijuana use so it is difficult to determine precisely why some of these differences exist.

\section{Limitations and Future Directions}

Although the current study has several strengths including the large samples in two countries with different legalization landscapes, there are also several limitations worth noting. These limitations include reliance on a single item regarding marijuana use, the use of cross-sectional data, as well as a limited set of predictors based on demographic characteristics of the sample assessed in both studies. Ideally, a more extensive battery of questions should be used to better highlight and explain different aspects of use (e.g., motives, method of marijuana use, contextual factors). In addition, the U.S. sample had been enrolled in college for a longer period of time than the Swedish sample. Further, although the response rates for the U.S. (54\%) and Sweden $(40 \%)$ studies were relatively low, these rates are consistent with other college studies using similar registrar-based recruitment methods (Graupensperger et al., 2021; Mallett et al., 2019). Future research may also benefit by utilizing data from several time points in order to determine temporality. In addition, although marijuana use for recreational purposes has been legalized in some U.S. states since the time of data collection (including the state in which data were collected for the current study), it remains illegal at the Federal level in the U.S. and was still illegal for recreational use at the state level at the time data were gathered in both countries (2007). Thus, gathering new data may be more informational regarding current trends and associations, as prevalence is now increased, and thus new correlates of use may be identified. Further, the quantity of marijuana use as well as negative marijuana-related consequences should be examined as an outcome in future research given their increased attention in the literature (e.g., Cuttler \& Spradlin, 2017) and cross-cultural differences found in previous studies (Bravo et al., 2019). This more nuanced approach to measuring both use and consequences would give further insight into potentially important cross-cultural similarities and differences for college marijuana use.

\section{Conclusions}

Despite these limitations, the study included large samples of students in both the U.S. and Sweden. Given that there are few studies that compare U.S. and Sweden college students' marijuana use, this comparison provides an interesting opportunity to compare a completely prohibitionist country (Sweden) with one with varying levels of legalization among states (U.S). The differing stances on legalization may account for some of the differences observed in the models, especially the higher rates of marijuana evidenced by the U.S. sample. In summary, this study identified some important similarities and differences regarding marijuana use among college students in the U.S. and Sweden. Overall, while results indicated consistent similarities in potential predictors across both countries, findings help showcase international similarities and differences, which may be useful to create a more unified harm-reduction based approach as they can help inform how prevention models for U.S. college students may be adapted to Swedish college students.

\section{References}

Arria, A. M., Caldeira, K. M., Bugbee, B. A., Vincent, K. B., \& O'Grady, K. E. (2016). Marijuana use trajectories during college predict health outcomes nine years postmatriculation. Drug and Alcohol Dependence, 159, $158-165$. https://doi.org/10.1016/j.drugalcdep.2015.12.009

Atkins, D. C., Baldwin, S. A., Zheng, C., Gallop, R. J., \& Neighbors, C. (2013). A tutorial on count regression and zero-altered count models for longitudinal substance use data. Psychology of Addictive Behaviors, 27(1), 166. https://doi.org/10.1037/a0029508

Bloom, D. \& Iordanidis, M. (2014) - Attityd och användning till cannabis bland studenter på Linnéuniversitetet: En kvantitativ undersökning [Attitudes and cannabis usage amongst students at the Linnaeus University: A quantitative study] [Bachelor's thesis, Linnaeus University]. $\quad$ http://nu.divaportal.org/smash/get/diva2:764872/FULLTEXT01.pdf 
Blomqvist, J. (2009). What is the worst thing you could get hooked on? Popular images of addiction problems in contemporary Sweden. Nordic Studies on Alcohol and Drugs, 26(4), 373-398. https://doi.org/10.1177/145507250902600404

Bravo, A. J., Pearson, M. R., Pilatti, A., Mezquita, L., \& Cross-Cultural Addictions Study Team. (2019). Negative marijuana-related consequences among college students in five countries: Measurement invariance of the Brief Marijuana Consequences Questionnaire. Addiction, 114(10), 1854-1865. https://doi.org/https://doi.org/10.1111/add.14646

Buckman, J. F., Yusko, D. A., Farris, S. G., White, H. R., \& Pandina, R. J. (2011). Risk of marijuana use in male and female college student athletes and nonathletes. Journal of Studies on Alcohol and Drugs, 72(4), 586-591. https://doi.org/510.15288/jsad.12011.15272.15586.

Bullock, S. (2004). Alcohol, Drugs and Student Lifestyle: A Study of the Attitudes, Beliefs and Use of Alcohol and Drugs among Swedish University Students. SoRAD Research Report nr 21. SoRAD Report Series. Retrieved Dec 12, 2004, from http://urn.kb.se/resolve?urn=urn:nbn:se:su:diva- 8519

Cuttler, C., \& Spradlin, A. (2017). Measuring cannabis consumption: Psychometric properties of the daily sessions, frequency, age of onset, and quantity of cannabis use inventory (DFAQ-CU). PLoS One, 12(5), $\mathrm{e} 0178194$.

https://doi.org/10.1371/journal.pone.0178194

Elliott, J. C., Carey, K. B., \& Vanable, P. A. (2014). A preliminary evaluation of a web-based intervention for college marijuana use. Psychology of Addictive Behaviors, 28(1), 288. https://doi.org/10.1037/a0034995

ESPAD Group. (2016). The 2015 ESPAD Report: Results from the European School Survey Project on Alcohol and Other Drugs. European Monitoring Centre for Drugs and Drug Addiction. https://www.emcdda.europa.eu/publications/jointpublications/emcdda-espad-report_en

European Monitoring Centre for Drugs and Drug Addiction (EMCDDA, 2017), European Drug Report 2017: Trends and Developments, Publications Office of the European Union, Luxembourg. https://www.emcdda.europa.eu/system/files/publication s/4541/TDAT17001ENN.pdf

European Monitoring Centre for Drugs and Drug Addiction (EMCDDA, 2019), European Drug Report 2019: Trends and Developments, Publications Office of the European Union, Luxembourg. https://www.emcdda.europa.eu/system/files/publication s/11364/20191724_TDAT19001ENN_PDF.pdf

Folkhälsomyndigheten [Swedish Authority of National Health and Welfare] (2018), data from the national PxWeb 2019 v1 survey, accessed Apr 22, 2020. http://fohm-

app.folkhalsomyndigheten.se/Folkhalsodata/pxweb/sv/ B_HLV/B_HLV_aLevvanor_aacLevvanornarkotika/

Graupensperger, S., Lee, C. M., \& Larimer, M. E. (2021). Young adults underestimate how well peers adhere to COVID-19 preventive behavioral guidelines. The
Journal of Primary Prevention, 1-10. https://doi.org/10.1007/s10935-021-00633-4

Han, B., Compton, W. M., Blanco, C., \& Jones, C. M. (2018). Trends in and correlates of medical marijuana use among adults in the United States. Drug and Alcohol Dependence, 186, 120-129. https://doi.org/10.1016/j.drugalcdep.2018.01.022

Hasin, D. S, Sarvet, A. L., Cerda, M., Keyes, K. M., Stohl, M., Galea, S., \& Wall, M. M. (2017). US adult illicit cannabis use, cannabis use disorder, and medical marijuana laws: 1991-1992 to 2012-2013. JAMA Psychiatry, 74(6), 579-588. https://doi.org/510.1001/jamapsychiatry.2017.0724.

Hilbe, J. M. (2011). Negative binomial regression ( $\left.2^{\text {nd }} \mathrm{ed}.\right)$. Cambridge University Press.

Jansson, N. (2014) Droganvändande och drogpreferenser bland universitetsstudenter vid LTU: En kvantitativ undersökning. [Drug usage and drug preferences amongst university students at LTU: A quantitative study] [Bachelor's thesis, Luleå University of Technology]. http://www.divaportal.org/smash/get/diva2:1016784/FULLTEXT02.pdf

Källoff, K., Thomasson, A., Wahlgren, L., \& Andersson, C. (2015) Hur mår våra studenter? [How are our students' doing?] Report from Malmö University, Mar 19, 2015/403.

https://muep.mau.se/bitstream/handle/2043/19692/Stud enthalsans_undersokning.pdf?sequence $=2$ \&isAllowed $=$ y

Karila, L., Roux, P., Rolland, B., Benyamina, A., Reynaud, M., Aubin, H. J., \& Lançon, C. (2014). Acute and longterm effects of cannabis use: A review. Current Pharmaceutical Design, 20(25), 4112-4118. https://doi.org/10.2174/13816128113199990620

Keith, D. R., Hart, C. L., McNeil, M. P., Silver, R., \& Goodwin, R. D. (2015). Frequent marijuana use, binge drinking and mental health problems among undergraduates. The American Journal on Addictions, 24(6), 499-506. https://doi.org/410.1111/ajad.12201

Lee, C. M., Neighbors, C., Kilmer, J. R., \& Larimer, M. E. (2010). A brief, web-based personalized feedback selective intervention for college student marijuana use: A randomized clinical trial. Psychology of Addictive Behaviors, 24(2), 265-273. https://doi.org/10.1037/a0018859

Lee, C. M., Kilmer, J. R., Neighbors, C., Atkins, D. C., Zheng, C., Walker, D. D., \& Larimer, M. E. (2013). Indicated prevention for college student marijuana use: A randomized controlled trial. Journal of Consulting and Clinical Psychology,81(4), 702. https://doi.org/10.1037/a0033285

Long, J. S. (1997) Regression models for categorical and limited dependent variables. Sage Publications Inc.

Lundgren, L. \& Uhlin, R. (2014) Ett universitet med eller utan cannabis? [A university with or without cannabis?] [Bachelor's thesis, Linköpings universitet]. http://www.divaportal.se/smash/get/diva2:730238/FULLTEXT01.pdf

Maggs, J. L., Staff, J., Kloska, D. D., Patrick, M. E., O'Malley, P. M., \& Schulenberg, J. (2015). Predicting young adult degree attainment by late adolescent 
marijuana use. Journal of Adolescent Health, 57(2), 205-211.

https://doi.org/10.1016/j.jadohealth.2015.04.028

Mallett, K. A., Turrisi, R., Reavy, R., Russell, M., Cleveland, M. J., Hultgren, B., Larimer, M. E., Geisner, I. M., \& Hospital, M. (2019). An examination of parental permissiveness of alcohol use and monitoring, and their association with emerging adult drinking outcomes across college. Alcoholism: Clinical and Experimental Research, 43(4),

$758-766$. https://doi.org/710.1111/acer.13978

Månsson, J. \& Ekendahl, M. (2015). Protecting prohibition: The role of Swedish information symposia in keeping cannabis a high-profile problem. Contemporary Drug Problems, 42(3), 209-225. https://doi.org/10.1177/0091450915599348

McCabe, S. E., Schulenberg, J. E., Johnston, L. D., O'Malley, P. M., Bachman, J. G., \& Kloska, D. D. (2005). Selection and socialization effects of fraternities and sororities on US college student substance use: A multi-cohort national longitudinal study. Addiction, 100(4), 512-524. https://doi.org/510.1111/j.1360-0443.2005.01038.x.

Palfai, T. P., Saitz, R., Winter, M., Brown, T. A., Kypri, K., Goodness, T. M., O'Brien, L. M., \& Lu, J. (2014). Webbased screening and brief intervention for student marijuana use in a university health center: Pilot study to examine the implementation of eCHECKUP TO GO in different contexts. Addictive Behaviors, 39(9), 13461352. https://doi.org/10.1016/j.addbeh.2014.04.025

Pearson, M. R., Bravo, A. J., Sotelo, M., \& Cross-Cultural Addictions Study Team. (2019). Cross-cultural examination of college marijuana culture in five countries: Measurement invariance of the Perceived Importance of Marijuana to the College Experience Scale. Addictive Behaviors, 96, 11-17. http:/doi.org/ 10.1016/j.addbeh.2019.04.004

Pearson, M. R., Liese, B. S., Dvorak, R. D., \& Marijuana Outcomes Study Team. (2017). College student marijuana involvement: Perceptions, use, and consequences across 11 college campuses. Addictive Behaviors, 66,

83-89. https://doi.org/10.1016/j.addbeh.2016.10.019

Polisen. (2017, April 24). Narkotikabrott - lagar och fakta. [Drug offenses - laws and facts] https://polisen.se/Lagaroch-regler/Om-olika-brott/Alkohol-ochnarkotikabrott/Fakta-omnarkotikabrott/

Public Health Agency of Sweden (2010). Narkotikabruket $i$ Sverige [Use of Drugs in Sweden]. Statens Folkhälsoinstitut.

https://www.folkhalsomyndigheten.se/contentassets/78 5864a3fd7a468fb5a39ba03dc6387b/r2010-13narkotikabruket-i-sverige.pdf

Public Health Agency of Sweden (2012). Levnadsvanor [Living habits]. Statens Folkhälsoinstitut.

Riggs, N. R., Conner, B. T., Parnes, J. E., Prince, M. A., Shillington, A. M., \& George, M. W. (2018). Marijuana eCHECKUPTO GO: Effects of a personalized feedback plus protective behavioral strategies intervention for heavy marijuana-using college students. Drug and Alcohol Dependence, 190, 13-19. https://doi.org/10.1016/j.drugalcdep.2018.05.020
Schulenberg, J.E., Johnston, L.D., O'Malley, P.M, Bachman, J.G., Miech, R.A., \& Patrick, M.E. (2018). Monitoring the Future national survey results on drug use, 1975-2017: Volume 2, College students and adults ages 19-55. Institute for Social Research, The University of Michigan. https://deepblue.lib.umich.edu/bitstream/handle/2027.4 2/148123/Overview\%202018\%20FINAL\%20print\%20 1-30.pdf? sequence $=1 \&$ isAllowed $=\mathrm{y}$

Shrier, L. A., Walls, C. E., Kendall, A. D., \& Blood, E. A. (2012). The context of desire to use marijuana: Momentary assessment of young people who frequently use marijuana. Psychology of Addictive Behaviors, 26(4), https://doi.org/10.1037/a0029197

Substance Abuse and Mental Health Services Administration (2019). Key substance use and mental health indicators in the United States: Results from the 2018 National Survey on Drug Use and Health (HHS Publication No. PEP19-5068, NSDUH Series H-54). Rockville, MD: Center for Behavioral Health Statistics and Quality, Substance Abuse and Mental Health Services Administration. Retrieved from https://www.samhsa.gov/data/

Substance Abuse and Mental Health Services Administration (SAMHSA, 2005). Results from 2004 National Survey on Drug Use and Health: Volume I. Summary of National Findings. Rockville, MD, Office of Applied Studies.

Substance Abuse and Mental Health Services Administration (SAMHSA, 2010). Results from 2009 National Survey on Drug Use and Health: Volume I. Summary of National Findings. Rockville, MD, Office of Applied Studies.

Suerken, C. K., Reboussin, B. A., Sutfin, E. L., Wagoner, K. G., Spangler, J., \& Wolfson, M. (2014). Prevalence of marijuana use at college entry and risk factors for initiation during freshman year. Addictive Behaviors, 39(1), 302-307. https://doi.org/10.1016/j.addbeh.2013.10.018

Sznitman, S. R., Kolobov, T., Ter Bogt, T., Kuntsche, E., Walsh, S. D., \& Harel-Fisch, Y. (2015). Investigating cannabis use normalization by distinguishing between experimental and regular use: A multilevel study in 31 countries. Journal of Studies on Alcohol and Drugs, $76(2)$, 181-189. https://doi.org/10.15288/jsad.2015.76.181

Tham, H. (2009). The issue of criminalization of drug use in Sweden. Nordic Studies on Alcohol and Drugs, 26(4), 432-435. https://doi.org/10.1177/145507250902600408

Wright, L.E., Palfai, T.P. (2012). Life goal appraisal and marijuana use among college students. Addictive Behaviors, $\quad 37, \quad 797-802$. https://doi.org/10.1016/j.addbeh.2012.02.020

Volkow, N. D., Baler, R. D., \& Compton, S. R. (2014). Adverse health effects of marijuana use. New England Journal of Medicine, 370(23), 2219-2227. https://doi.org/10.1056/NEJMra1402309 